Final draft. Forthcoming in Thought.

\title{
Testimonial Injustice Without Credibility Deficit (or Excess)
}

\author{
Federico Luzzi
}

\section{Introduction}

Miranda Fricker (2007) has introduced and influentially discussed testimonial injustice: the injustice done to a speaker $\mathrm{S}$ by a hearer $\mathrm{H}$ when, due to a negative identity-prejudicial stereotype she holds about $\mathrm{S}, \mathrm{H}$ unjustly accords too little credibility to S. Here I explore an overlooked possibility: forms of testimonial injustice that do not involve the hearer $\mathrm{H}$ giving too little credibility to the speaker S. Rather, they involve $\mathrm{H}$ giving due credibility to S, i.e. exactly the amount of credibility S merits. I will raise considerations suggesting that these are genuine forms of testimonial injustice. If these are persuasive, then the contours of testimonial injustice should be redrawn to include them. If they are not persuasive, then either a new form of epistemic injustice is uncovered, since it would fit the mould of neither of the two kinds of injustice Fricker discusses (i.e., testimonial and hermeneutical injustice ${ }^{1}$ );

\footnotetext{
${ }^{1}$ Hermeneutical injustice is, roughly, the harm suffered by victims of an injustice when their community lacks the conceptual resources to recognise it as an injustice. Fricker's key example is sexual harassment, which for a long time was not recognised as a distinctive kind of harm.
} 
or an important exegetical result is reached, and the underspecified notion of 'credibility' finds a mandated reading. In all cases, the philosophical upshot is noteworthy.

I proceed as follows: First, I present Fricker's account of testimonial injustice. Then I focus on the lead-up to this account, in which Fricker provides her argument for ruling out credibility excess-based cases as a central kind of testimonial injustice. I will also examine her reasons for deeming a specific credibility deficit-based case not to be a central kind of testimonial injustice. From this discussion three conditions emerge that must be met by central cases of testimonial injustice. I then describe two different kinds of testimonial injustice with due credibility and show that they both meet these criteria. I close by discussing three objections to my cases.

\section{Testimonial Injustice}

According to Fricker, a speaker suffers testimonial injustice when she is accorded too little credibility due to a negative identity-prejudicial stereotype. This is defined as

\footnotetext{
[a] widely held disparaging association between a social group and one or more attributes, where this association embodies a generalisation that displays some (typically, epistemically culpable) resistance to counter-evidence owing to an ethically bad affective investment (35)
}

It will be helpful to illustrate testimonial injustice with two incisive literary examples invoked by Fricker. The first comes from Harper Lee's To Kill a Mockingbird. Here, the white racist jurors commit testimonial injustice when they don't believe Tom Robinson's claim to innocence because he is black. This injustice leads to his conviction, despite the evidence being clearly incompatible with his guilt. The second is drawn from Antony Minghella's 
The Talented Mr Ripley, where Marge Sherwood's voicing of the possibility that her missing fiancé Dickie has been murdered is summarily dismissed by Dickie's father, Herbert Greenleaf, with the sexist quip 'Marge, there's female intuition, and then there are facts'. What makes both cases instances of testimonial injustice, according to Fricker, is that the hearer(s) fail(s) to give the speaker the credibility they deserve owing to negative identityprejudicial stereotype, of which the jurors' racism and Greenleaf's sexism are examples.

\section{Three cases, three constraints}

Early on in her discussion, Fricker writes:

Broadly speaking, prejudicial dysfunction in testimonial practice can be of two kinds. Either the prejudice results in the speaker's receiving more credibility than she otherwise would have - a credibility excess - or it results in her receiving less credibility than she otherwise would have - a credibility deficit. (17)

This remark sets the scene for Fricker's discussion and ultimate ruling out of credibility-excess-based examples from being central cases of testimonial injustice. However, a third option, according to which some prejudicial dysfunction in testimonial practice may result in the speaker being given the right amount of credibility, is overlooked. I develop discussion of the third option in the next section. But it will be instructive beforehand to trace Fricker's argument against credibility excess-based testimonial injustice.

Fricker considers the possibility that testimonial injustice might come about by way of a hearer being afforded too much credibility. However, two cases she adduces ultimately tell against this possibility. 


\subsection{Case 1: the GP}

Fricker considers the case of a doctor - a general practitioner - whose patients substantially overestimate her expertise across a wide range of specialisms. It is assumed that she is the only doctor who can advise and care for them and that admitting her lack of expertise would compromise the trust between her and her patients. Thus, she provides the best advice and care she can, while fully realising — with an appropriate sense of discomfort - that these fall short of the medical support a specialist could provide. In this situation the doctor suffers a disadvantage on account of the credibility excess her patients give her, in the shape of an unwanted ethical burden.

Is this a case of testimonial injustice? Fricker thinks it is not, because the kind of disadvantage suffered by the doctor is not of a distinctively epistemic kind:

The idea is to explore testimonial injustice in which someone is wronged specifically in her capacity as a knower. Clearly credibility deficit can constitute such a wrong, but while credibility excess may (unusually) be disadvantageous in various ways, it does not undermine, insult, or otherwise withhold a proper respect for the speaker qua subject of knowledge; so in itself it does her no epistemic injustice, and a fortiori no testimonial injustice. (20, original emphasis)

The disadvantage suffered by the doctor is non-epistemic and therefore she is not the victim of testimonial injustice. It is important to note that the constraint that the injustice harm the victim in her capacity as a knower flows from the broader category of epistemic injustice, of which testimonial injustice is an instance: in fact, in Fricker's view it is 'definitive' of epistemic injustices that they harm their victims in this way. (44) 


\subsection{Case 2: the Non-Virtuous Cogniser}

Fricker discusses a further putative case of credibility-excess-based testimonial injustice: suppose that over the course of his life a person is consistently afforded too much credibility, so that he is systematically deferred to by those around him. Consequently, he becomes epistemically arrogant, impervious to criticism, and insensitive to counter-evidence. This is a cost: the excessive credibility he is afforded eventually prevents him from developing into an epistemically virtuous subject.

Is he the victim of testimonial injustice for the epistemic harm he suffers? Fricker admits that he might be subject to a "variant strain of testimonial injustice: namely, testimonial injustice in its strictly cumulative form' (21). But because the harm only comes about cumulatively, this cannot be a central kind of testimonial injustice, since for the latter, each individual instance harms the speaker. The examples of Tom Robinson and Marge Sherwood are cases in point: both are harmed by the injustice on the occasion it occurs, not solely by the cumulative effects of the injustice. She thereby concludes:

The primary characterisation of testimonial injustice, then, remains such that it is a matter of credibility deficit and not credibility excess. (21)

\subsection{Case 3: the Scientist}

A further instructive case ruled out by Fricker is instead based on credibility deficit. Imagine that a scientist submits a paper detailing her recent findings to an academic journal. Unfortunately, all the referees on the journal's panel are mistakenly and dogmatically prejudiced against the methodological framework within which the scientist works. As a result, the referees reject offhand the scientist's testimony, brought to them in the form of her findings 
in the scientific paper. Is the scientist a victim of testimonial injustice?

Fricker thinks that while this scientist is the victim of testimonial injustice, this is of an incidental, highly localized, and therefore non-central form. The central cases of testimonial injustice are instead systematic, i.e., they 'track the subject through different dimensions of social activity-economic, educational, professional, sexual, legal, political, religious, and so on' (27). This dovetails with the paradigmatic examples of Marge Sherwood and Tom Robinson: the gender and race of these characters make them systematic targets of the harm of testimonial injustice in their respective settings.

\subsection{Three constraints}

From Fricker's discussion three constraints on central forms of testimonial injustice emerge:

1. Wronged-as-a-knower: the harm wrongs the victim in her capacity as a knower

2. Non-cumulative: the harm is not solely constituted by the cumulative effects of the injustice

3. Systematic: the harm tracks the subject in a vast range of domains (social, political, economic, etc.)

\section{Testimonial Injustice with Due Credibility}

I will now describe two independent types of cases of putative testimonial injustice with due credibility. I label these 'Type I' and 'Type II' cases.

An example of Type I case is this: Imagine a society where a certain minority group $\mathrm{G}$ is stigmatized in the following way: non-Gs believe that 
Gs are sincere and tell the truth most of the time-just as much as any member of society does. Non-Gs also dogmatically and falsely believe that the beliefs held by members of Gs are systematically 'Gettiered' by some divine being, so that the beliefs held by Gs are justified and true, but not known by Gs. ${ }^{2}$ As a result, while non-Gs believe that what Gs say is true, and routinely accept the content of Gs' testimony, non-Gs also take the view that Gs don't know any of the propositions they (i.e., Gs) assert.

For example, suppose Selma belongs to group G and Hosni doesn't. Selma sees a barn in the field by the petrol station and, some time later, reports to Hosni 'There is a barn in the field by the petrol station'. Hosni truly believes that Selma is sincere, but he also falsely and dogmatically thinks that Selma is systematically 'Gettiered', i.e. that her perceptual beliefs, including the one whose content she just asserted, are true, justified but not known. Consequently, Hosni accepts Selma's testimony as true. It is important to stress that Hosni takes Selma to be credible - just as credible, we may stipulate, as any other honest and sincere testifier. If a non-G had made the same assertion, Hosni's confidence that there is a barn in the field by the petrol station would be exactly the same. The only difference is that if a non-G had said 'There is a barn in the field by the petrol station', Hosni would have taken the non-G speaker to know the proposition expressed by the assertion (or Hosni would have had no view on this issue), whereas he negatively judges Selma not to know the content of her assertion.

In a society like this, the injustice suffered by members of $G$ meets Fricker's criteria:

1. Gs are routinely wronged as knowers: whenever a member of G tes-

\footnotetext{
${ }^{2}$ See Gettier (1963) for the original Gettier-type cases. I use 'Gettiered' to refer to any belief that is justified, true but not known.
} 
tifies that $\mathrm{p}$ to a non-G, they are believed, but they are regarded by their audience as not knowing p. Therefore, this injustice does 'undermine, insult, or otherwise withhold a proper respect for the speaker qua subject of knowledge' (20).

2. The harm involved is not strictly cumulative: on each occasion in which a member of $\mathrm{G}$ gives testimony to a non-G, the latter fails to regard the $\mathrm{G}$ as a knower and the member of $\mathrm{G}$ is thereby wronged as a knower.

3. The harm is systematic: because non-Gs fail to regard members of $G$ as knowers of what they say regardless of the topic, the epistemic harm they suffer tracks them across virtually all dimensions of social activity.

The second, independent type of case - Type II cases - are in all but one respect similar to Type I cases. The only difference is that instead of non-Gs regarding the beliefs held by Gs as Gettiered, non-Gs regard the beliefs held by Gs as true but not doxastically justified. Perhaps, for instance, non-Gs believe that Gs have generally truth-conducive belief-forming mechanisms, but also believe that once Gs form their beliefs, a cognitive malfunction leads Gs to sustain their beliefs with completely irrelevant considerations, so that Gs' beliefs are true but never appropriately epistemically based. In other words, non-Gs falsely and dogmatically believe that the reasons Gs have in support of their (i.e., Gs') beliefs are inadequate, and truly believe that Gs' beliefs are true. In this way, non-Gs believe that Gs don't know the propositions they assert, even though they (i.e., non-Gs) routinely accept them (quite correctly, in fact) as true. It is easy to see that, as for Type I cases, Type II cases also meet the three criteria above.

Type I and Type II cases show how one can systematically and noncumulatively be harmed in one's capacity as a knower without this harm 
taking the shape of being afforded less-than-merited credibility. Because the reasons for ruling out the centrality of credibility-excess-based injustices do not also apply to this due-credibility-based case, there is at least presumptive reason to take these to be cases of testimonial injustice proper. The reason is not conclusive, because Fricker is silent on whether these three constraints are jointly sufficient for testimonial injustice. But, I submit, there are strong enough reasons at least to explore the prospects of considering them to be cases of testimonial injustice.

\section{$5 \quad$ Three objections}

One might object that the cases I have proposed bear little connection with real life. Recognising their existence, then, does not promise the possibility of an ethical improvement in the way we treat others. The situation is dissimilar to the central cases of Fricker's focus, which do have the potential for wide-ranging socio-epistemic and ethical change.

I offer two responses. The first is that, while admittedly Type I cases are far-fetched, it is less clear that Type II cases are not instantiated. For example, the phenomenon of 'mansplaining', wherein a man explains to a woman why something she just asserted is true, can be well-accounted for by positing that some men's attitude towards women is precisely the one at work in Type II cases: these men think what women say is true, but that women don't hold good reasons for believing what they believe. ${ }^{3}$

But the second, more fundamental reply is that whether these cases are actually instantiated is irrelevant. When doing philosophy, we map out logical space; whether a kind of case is possible is not settled negatively by the

\footnotetext{
${ }^{3}$ I am grateful to Bernhard Salow for this observation.
} 
fact that such a case is rare: just like the possibility of Gettier's original cases is not impugned by the claim that they are seldom instantiated, so the concession that cases of Type I and II rarely - if ever - obtain does not affect the claim that cases of testimonial injustice with due credibility are possible.

A second objection is that Fricker defines testimonial injustice as the harm done by a hearer to a speaker when the former gives less credibility to the hearer than she deserves, owing to prejudice. So, by definition, cases of testimonial injustice with due credibility are impossible.

Two replies are available here, one direct, one concessive. The direct reply is to say that, rather than ruling out these cases to accommodate the definition, one ought to modify the definition to accommodate these cases. It is significant in this respect that the considerations Fricker uses to rule out credibility-excess-based testimonial injustice do not rule out due-credibilitybased testimonial injustice, and that Fricker never so much as considers cases of the latter kind. Perhaps, had Fricker lent consideration to the possibility of Type I and Type II, she herself would have recognised the propriety of a broader definition of testimonial injustice.

Additionally, there are substantial similarities between the key cases of testimonial injustice provided by Fricker and Type I and Type II cases, which make the latter cases deserving of the label 'testimonial injustice'. Like Fricker's examples, Type I and II cases describe an injustice of an epistemic nature. And like Fricker's examples, Type I and II cases arise only in the context of the reception, by the perpetrator, of a specific testimonial act produced by the victim of the injustice. This similarity, it may be argued, is distinctive enough to warrant subsuming all these cases under the same notion.

If this is persuasive, then we have a neat explanation of the existence 
of testimonial injustice with due credibility and a more appropriate broader definition. One can define testimonial injustice as the harm done by a speaker to a hearer when, due to negative identity-prejudicial stereotype, the former regards the latter as failing to know the content of their testimony. This is compatible with due credibility being given to the speaker, because being given less credibility than one deserves does not exhaust the ways in which one can be regarded as failing to know.

But perhaps not everyone will be persuaded by the direct reply. Some might be adamant that Fricker's definition as stated is correct, and that there simply cannot be testimonial injustice with due credibility. The concessive reply to this objection is to grant this point, and then to observe that the cases at issue must still be regarded as news. After all, they meet Fricker's definition of epistemic injustice - in both Type I and Type II cases, the speaker is harmed by the hearer in her capacity as a knower (since nonGettierization and doxastic justification are required for knowledge), and it is a prejudice-driven epistemic dysfunction that causes the speaker harm. Additionally, (granting the point) they are not cases of testimonial injustice. Nor, crucially, are they instances of the only other kind of epistemic injustice Fricker discusses: hermeneutical injustice, wherein the subject is harmed due to her community's lack of epistemic and conceptual resources required to recognise and identify the wrong she suffers as a wrong. Thus, they represent a new form of epistemic injustice, distinct from the testimonial and hermeneutical varieties discussed by Fricker.

A third objection raises the possibility that both Type I and Type II cases can be accommodated on Fricker's account when this is charitably interpreted. ${ }^{4}$ The crucial matter is what '(due) credibility' means on Fricker's

\footnotetext{
${ }^{4}$ Thanks to an anonymous referee for raising this objection.
} 
view. If giving due credibility to $\mathrm{S}$ entails regarding $\mathrm{S}$ as a testifier whose claims are merely true, then Type I and Type II cases have a good claim to being cases of due-credibility based testimonial injustice, because nonGs regard the testimony of Gs as true. If, on the other hand, giving due credibility to $\mathrm{S}$ entails (more substantially) regarding $\mathrm{S}$ as a testifier who speaks from knowledge, then both Type I and Type II cases could be thought of as cases of testimonial injustice based on credibility deficit, since non-Gs do not regard Gs as knowledgeable. In this latter case, Fricker's account would be under no pressure of amendment.

Which of these interpretations of due credibility is Fricker committed to: the 'regard-S-as-truthful' or the 'regard-S-as-knowledgeable' reading? Fricker does not provide much detail. One remark made en passant supports the view that Fricker interprets credibility primarily as the extent to which $\mathrm{H}$ regards S's testimony as true, rather than knowledgeable:

Epistemological nuance aside, the hearer's obligation is obvious: she must match the level of credibility she attributes to her interlocutor to the evidence that he is offering the truth. (19, my emphasis)

If Fricker espoused the stronger notion of credibility, according to which giving due credibility requires regarding the speaker as knowledgeable, one would expect her to maintain that the hearer's obligations are to match the attributed level of credibility to the evidence that the speaker knows the content of her testimonial offering.

At a different juncture, however, Fricker suggests that a credibility judgment should be understood 'in terms of the hearer perceiving the speaker as more or less trustworthy on the matter in question' (70-1, original emphasis), and that trustworthiness comprises sincerity and competence (45). However, the notion of competence is not given further elucidation. Since non-Gs in 
Type I and II cases deem Gs to be sincere, whether non-Gs give due credibility to Gs turns on whether non-Gs take Gs to be competent. If competence requires knowledge, then clearly no due credibility is given. If it does not, then Type I and II cases may exhibit due credibility. ${ }^{5}$

It's unclear that this third objection succeeds. It's also unclear that it fails. It all depends on how 'competence' is understood, which in turn determines how 'trustworthiness' and 'due credibility' are construed. Regardless of the success of the objection, Type I and Type II cases advance the debate, because they highlight, for the first time, that the ability of Fricker's account to accommodate these cases as credibility-deficit-based testimonial injustice turns on endorsing a particular interpretation of 'credibility' - an issue which Fricker has not taken a detailed stand on. The interesting result is that if Fricker wishes to deny that testimonial injustice with due credibility is possible, then (barring an expansion of the taxonomy of epistemic injustices), she is forced to endorse a strong reading of credibility, according to which giving due credibility requires deeming the speaker to know the content of their testimony.

\section{Conclusion}

I have explored the prospects for testimonial injustice with due credibility. Type I and Type II cases provide presumptive reason to think testimonial injustice with due credibility is possible, given Fricker's discussion of testimonial injustice. Is this enough to think that testimonial injustice with due credibility is indeed possible? If so, then Fricker's account of testimo-

\footnotetext{
${ }^{5}$ Type I cases have a stronger claim to exhibiting speakers deemed to be competent by hearers. However, if reliable truth-telling suffices for competence, then hearers will also deem speakers to be competent in Type II cases.
} 
nial injustice is broadened; if not, then either our taxonomy of epistemic injustice is enriched by a novel kind of injustice, or a specific interpretation of 'credibility' that allows it to accommodate Type I and Type II cases is mandated. ${ }^{6}$

\section{References}

Fricker, M. (2007). Epistemic injustice: Power and the ethics of knowing. Oxford: Oxford University Press.

Gettier, E. (1963). Is justified true belief knowledge? Analysis, 23, 121-123.

\footnotetext{
${ }^{6}$ I am grateful to Bernhard Salow for helpful discussion, and to audiences at the Pragmatics and Testimony workshop at the University of Trieste and at the Puzzles of Knowledge workshop at the University of Lisbon.
} 